\title{
A kinetic study of ammoniation of straw either via the hydrolysis of urea or by anhydrous ammonia
}

\author{
S Sahnoune, L Girard, JM Besle, M Chenost
}

INRA, Station de Recherches sur la Nutrition des Herbivores, 63122, Saint-Genès-Champanelle, France

The aim of this work was to compare the kinetics of straw upgrading using ammonia either in anhydrous form or from urea hydrolysis.

Wheat straw was ground ( $1 \mathrm{~cm}$ screen) and treated at $30^{\circ} \mathrm{C}$, in closed glass jars of $850 \mathrm{ml}$, by iso-ammonia doses $(5.3 \mathrm{~g} / 100 \mathrm{~g}$ straw DM), coming from $1^{\circ}$ urea and ground soybean (1.6 g/100 $\mathrm{g}$ straw DM) (US), moistened at $30 \% ; 2^{\circ}$ anhydrous ammonia, $(\mathrm{AA})$ at $30 \%$ straw moisture $\left(\mathrm{AA}_{30}\right)$, and $3^{\circ}$ $A A$ at $15 \%$ straw moisture $\left(A A_{15}\right)$. On opening, the samples were dried at $35^{\circ} \mathrm{C}$, nitrogen (Kjeldahl) and urea were determined. Organic matter digestibility (OMDd) was estimated by densitometry (Besle et al, 1989).

After $A A$, the fixation of $N$ rapidly reached a maximum (in $10 \mathrm{~d}$, fig 1a), while the increase of OMDd was more progressive (fig $1 \mathrm{~b}$ ). After US, the same pattern was observed, but at a lower rate. This was due to the slow ureolysis, but also, mainly for OMDd, to the coproducts of ammonia formation, carbamate, $\mathrm{CO}_{3}-$, which reduced the $\mathrm{pH}$ of the medium. However, after 4 weeks, OMDd of US and $\mathrm{AA}_{15}$ straws were close.

In conclusion, It is likely that, in upgrading straw with urea, the kinetics of nitrogen and energetic values differ, but after a while, the maximal values reached are close to that reached with $A A$, especially with the usual $A A_{15}$.

Besle JM, Signoret C, Chenost M, Aufrere J, Jamot $J$ (1989) In: Evaluation of Straws in Ruminant Feeding (Chenost M, Reiniger $P$, eds) Elsevier, London, 134-143

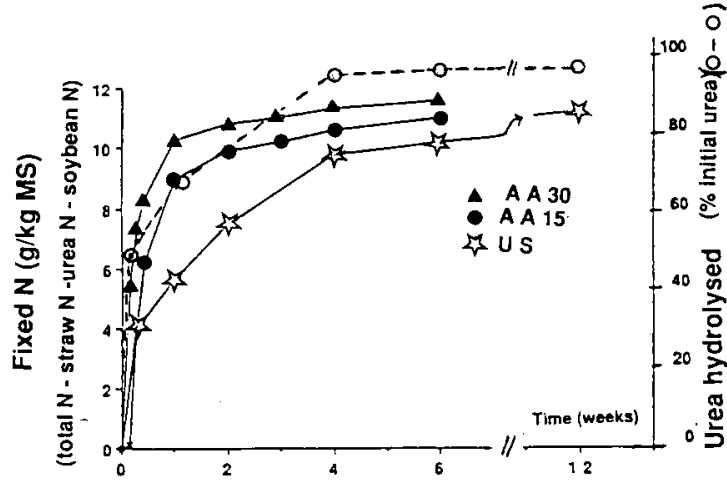

a

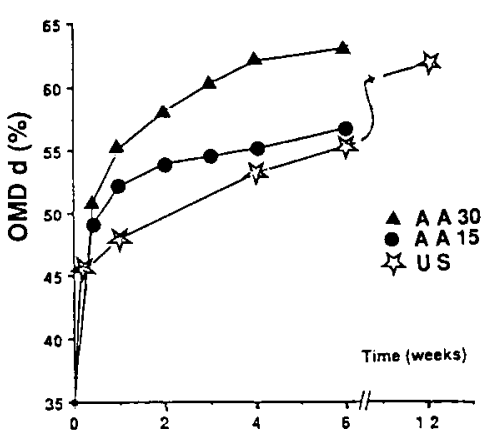

b

Fig 1. (a) Ureolysis, fixed $\mathrm{N}$; and (b) OMDd, of AA and US treated straws. 